\title{
Climate Factors and Their Effects on the Prevalence of Rhinovirus Infection in Cheonan, Korea
}

\author{
Dong Kyu Lim ${ }^{1 \dagger}$, Bo Kyeung Jung ${ }^{2 \dagger}$, and Jae Kyung Kim* \\ ${ }^{1}$ Department of Medical Laser, Dankook University Graduate School of Medicine, Cheonan 31116, Republic of Korea \\ ${ }^{2}$ Department of Laboratory Medicine, Dankook University College of Medicine, Cheonan 31116, Republic of Korea \\ ${ }^{3}$ Department of Biomedical Laboratory Science, College of Health Sciences, Dankook University, Cheonan 31116, Republic of Korea
}

Received: November 17, 2020 / Revised: February 14, 2021 / Accepted: February 14, 2021

\begin{abstract}
The use of big data may facilitate the recognition and interpretation of causal relationships between disease occurrence and climatic variables. Considering the immense contribution of rhinoviruses in causing respiratory infections, in this study, we examined the effects of various climatic variables on the seasonal epidemiology of rhinovirus infections in the temperate climate of Cheonan, Korea. Trends in rhinovirus detection were analyzed based on 9,010 tests performed between January 1, 2012, and December 31, 2018, at Dankook University Hospital, Cheonan, Korea. Seasonal patterns of rhinovirus detection frequency were compared with the local climatic variables for the same period. Rhinovirus infection was the highest in children under 10 years of age, and climatic variables influenced the infection rate. Temperature, wind chill temperature, humidity, and particulate matter significantly affected rhinovirus detection. Temperature and wind chill temperature were higher on days on which rhinovirus infection was detected than on which it was not. Conversely, particulate matter was lower on days on which rhinovirus was detected. Atmospheric pressure and particulate matter showed a negative relationship with rhinovirus detection, whereas temperature, wind chill temperature, and humidity showed a positive relationship. Rhinovirus infection was significantly related to climatic factors such as temperature, wind chill temperature, atmospheric pressure, humidity, and particulate matter. To the best of our knowledge, this is the first study to find a relationship between daily temperatures/wind chill temperatures and rhinovirus infection over an extended period.
\end{abstract}

Keywords: Climate, rhinovirus, meteorology, respiratory infection

\section{Introduction}

Respiratory infections are among the most common diseases for all age groups, and are an important cause of morbidity and mortality in children; more than 4 million children die annually from respiratory infections worldwide [1,2]. Acute respiratory infections in the United States reportedly account for $53 \%$ of all acute illnesses and $36 \%$ of school absences [3]. In Korea, respiratory infections account for $17-25 \%$ of children admitted

\section{*Corresponding author}

Tel.: +82-41-550-1451, Fax: +82-41-559-7934

E-mail: nerowolf@naver.com

${ }^{\dagger}$ These authors contributed equally to this work. to general hospitals [4-6]. Recently, the frequency of respiratory infections has increased due to climate change-related factors such as abnormal temperatures and environmental pollution [1, 7-9]. In Korea, the frequency and duration of yellow dust and particulate matter pollution events have increased steadily. As a result, the number of patients with asthma and lung disease has also increased, and there is a possibility that viruses may be introduced through yellow dust $[10,11]$.

The viruses most commonly found in patients with viral upper respiratory tract infections include rhinoviruses, coronaviruses, influenza viruses, parainfluenza viruses, and adenoviruses, with infection by rhinoviruses accounting for more than $50 \%$ of all cases [11]. 
Therefore, rhinovirus infection may be the most common acute infection in humans [7, 8, 12-14]. Rhinoviruses can be classified into picornaviruses (Picornaviridae) and enteroviruses (Enterovirus). They are the leading cause of the common cold and runny nose (acute rhinitis), and more than 100 serotypes are known [2]. In general, rhinoviruses are the cause of non-thermal upper respiratory tract infections [4, 15-17]. Rhinovirus symptoms typically appear approximately $20 \mathrm{~h}$ after infection. A previous study [18] accounted for the meteorological parameters 3 days prior to patient visits to the clinic, and found that the average incubation time before symptom onset was 1.9 days. Currently, there are no commercial vaccines against most respiratory viruses (RVs), except for influenza A and B [19], and effective prevention and control of viral infections remains difficult. Therefore, research on various patient populations, climate factors, and environmental factors will help in the prevention and treatment of respiratory viral diseases [20, 21].

Climate change and environmental destruction are the main factors associated with the increased spread of new viruses [9, 10]. Therefore, the aim of this study was to investigate the effects of various climatic variables on the seasonal epidemiology of respiratory infections, specifically rhinovirus infections, in a temperate climate. By anticipating and preparing for an infectious disease epidemic according to climatic variables, hospitalization periods can be shortened through rapid diagnosis and treatment, and the occurrence of infections can be reduced by taking preventive measures against the anticipated infectious diseases, thereby reducing social and economic costs [22].

\section{Materials and Methods}

\section{Sample collection}

This was a retrospective study based on respiratory virus reverse transcription-quantitative PCR (RT-qPCR) results. All respiratory samples used in the study were obtained as nasal swabs, throat swabs, and non-pharyngeal aspirates of patients with suspected respiratory diseases from January 1, 2012 to December 31, 2018. These samples were sent to the medical laboratory at the Dankook University School Hospital in
Cheonan City, Republic of Korea for RT-qPCR analysis. We collected a single sample from each patient and did not include duplicate tests performed on the same date in our analysis. If the same patient was hospitalized more than once, all hospitalizations were included in the examination. Outpatient samples were excluded from the data analysis. The samples were either tested immediately after collection or were refrigerated at $4{ }^{\circ} \mathrm{C}$ (if testing was not immediately available) and tested within $24 \mathrm{~h}$.

\section{Ethics}

This study was approved by the Institutional Review Board (IRB) of Dankook University (No. 2019-12-007). Data did not contain personal or identifiable information, and therefore the requirement of patient consent for the use of these data was waived.

\section{RT-qPCR analysis}

RNA was extracted from the collected specimens using QIAamp MinElute Virus Spin Kit (Qiagen GmbH, Germany). The extracted nucleic acids were amplified and probed for RVs using the AdvanSure RV real-time RT-PCR kit (LG Life Science Ltd., Korea) according to the manufacturer's instructions.

\section{Climatic variables}

Cheonan, Chungcheongnam-do, Korea $\left(36.47^{\circ} \mathrm{N}\right.$, $127.13^{\circ} \mathrm{E}$ ) has an area of $636.3 \mathrm{~km}^{2}$ and a typical temperate climate. The weather data for the Cheonan region from January 1, 2012 to December 31, 2018 were obtained from the Korea Meteorological Administration, and particulate matter data were obtained from the National Institute of Environmental Research; dailyautomated surface observing system (ASOS) data and particulate matter concentration data were collected. Climate data, including precipitation ( $\mathrm{mm})$, air temperature $\left({ }^{\circ} \mathrm{C}\right)$, wind chill temperature $\left({ }^{\circ} \mathrm{C}\right)$, daily temperature range $\left({ }^{\circ} \mathrm{C}\right)$, humidity $(\%)$, atmospheric pressure $(\mathrm{hPa})$, and particulate matter concentration $\left(\mu \mathrm{g} / \mathrm{m}^{3}\right)$, were used in the analysis. Wind chill temperature was calculated using the formula $13.12+0.6215 \times \mathrm{T}-11.37 \mathrm{~V}^{0.16}+$ $0.3965 \mathrm{~V}^{0.16} \times \mathrm{T}$, where $\mathrm{T}$ is the air temperature and $\mathrm{V}$ is the wind speed $(\mathrm{km} / \mathrm{h})$ measured at $10 \mathrm{~m}$ above the ground. 


\section{Statistical analysis}

SAS version 9.4 (SAS Institute Inc., USA) was used to perform descriptive statistical analysis, frequency analysis, $t$-tests, and binomial logistic regression analysis to investigate the relationship of meteorological variables and particulate matter concentrations with rhinovirus infection detection. For all analyses, statistical significance was set at $p<0.05$. The Shapiro-Wilk test was used to determine the normality of the data, and twotailed tests were performed to test the statistical significance.

\section{Results}

During the study period, 1,920 rhinovirus results were obtained, with $36.88 \%(\mathrm{n}=708)$ and $52.19 \%(\mathrm{n}=1,002)$ from children under 1 year and 1-9 years of age, respectively (Table 1). The detection rate of rhinovirus was higher in males $(60.16 \%)$ than in females (39.84\%). In total, 1,243 patients were infected only with rhinovirus, and 677 patients were simultaneously infected with other RVs. Among the targeted age groups, those under the age of 10 had the highest rate of rhinovirus infection (89\%) during the study period and the most significant results. Of note, the high rate of infection in those under the age of 10 affected the results. The number of patients infected with rhinovirus decreased sharply during the winter and increased in the spring (April to June) as the temperature began to rise (Fig. 1).

Fig. 2 shows the associations of rhinovirus infection with temperature, wind chill temperature, atmospheric pressure, and particulate matter concentration. The
Table 1. Patient demographics.

\begin{tabular}{lcc}
\hline & \multicolumn{2}{c}{ Rhinovirus cases } \\
\hline Age (years) & $\mathrm{N}$ & $\%$ \\
$<1$ & 708 & 36.88 \\
$1-9$ & 1,002 & 52.19 \\
$10-19$ & 99 & 5.16 \\
$20-29$ & 9 & 0.47 \\
$30-39$ & 6 & 0.31 \\
$40-49$ & 3 & 0.16 \\
$50-59$ & 13 & 0.68 \\
60 and above & 80 & 4.17 \\
Sex & & \\
Male & 1,155 & 60.16 \\
Female & 765 & 39.84 \\
No. of viruses detected & & \\
1 (only rhinovirus) & 1,243 & 64.74 \\
2 & 585 & 30.47 \\
3 & 88 & 4.58 \\
4 & 4 & 0.21 \\
\hline
\end{tabular}

concentration of particulate matter was high from November to May, and the wind chill temperature rose rapidly during the spring and early summer (Fig. 2). The air and wind chill temperatures, daily temperature range, humidity, and particulate matter concentration differed significantly between the days on which rhinovirus infection was detected and those on which no infection was detected, according to $t$-tests (Table 2). The average air and wind chill temperatures were higher on days on which rhinovirus infections were detected. Both the average daily temperature range and humidity were

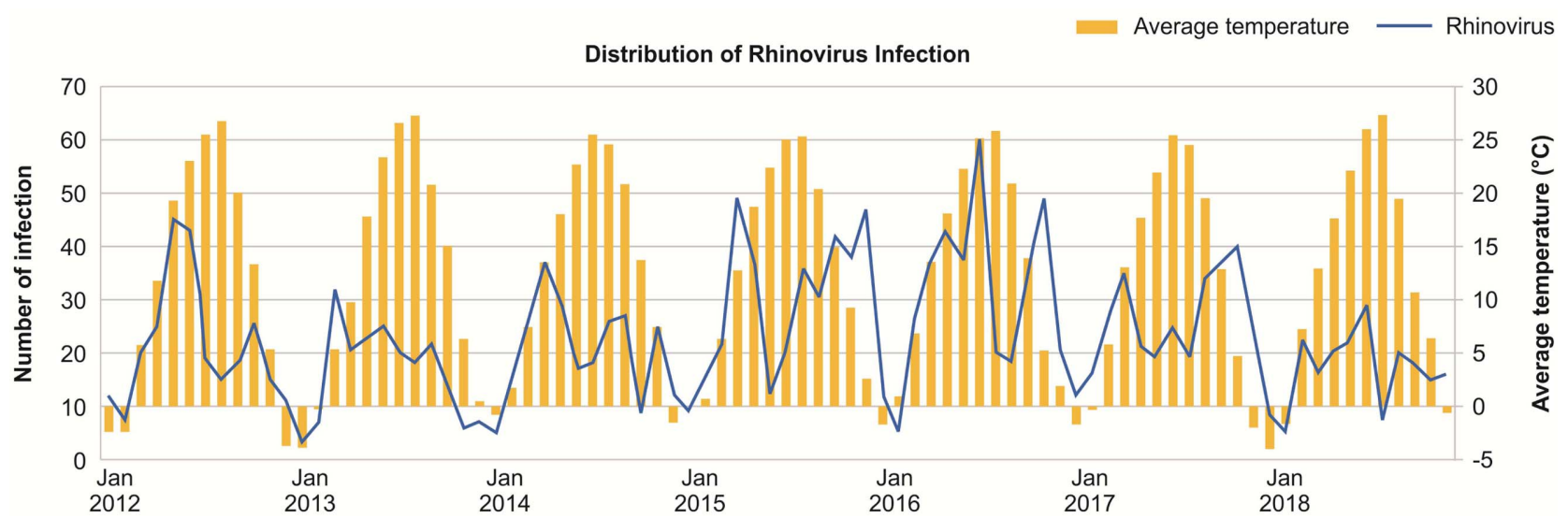

Fig. 1. Temporal distribution of rhinovirus infections from January 2012 to December 2018. 
Table 2. Difference in climatic variables according to days on which rhinovirus infection was detected.

\begin{tabular}{|c|c|c|c|c|c|c|c|}
\hline \multirow[t]{2}{*}{ Virus } & \multirow[t]{2}{*}{ Climatic variables } & \multicolumn{2}{|c|}{$\begin{array}{l}\text { Mean climatic values on days } \\
\text { rhinovirus was }\end{array}$} & \multirow{2}{*}{$\begin{array}{l}\text { Difference in } \\
\text { means }\end{array}$} & \multicolumn{2}{|c|}{$95 \% \mathrm{Cl}$} & \multirow[t]{2}{*}{$p$-value ${ }^{a}$} \\
\hline & & Detected & Not detected & & Lower & Upper & \\
\hline \multirow[t]{7}{*}{ Rhinovirus } & Precipitation (mm) & 3.10 & 2.60 & 0.50 & -0.04 & 1.04 & 0.067 \\
\hline & Air temperature $\left({ }^{\circ} \mathrm{C}\right)$ & 14.27 & 10.23 & 4.05 & 3.54 & 4.56 & $<0.0001$ \\
\hline & Wind chill temperature $\left({ }^{\circ} \mathrm{C}\right)$ & 13.89 & 9.53 & 4.36 & 3.82 & 4.90 & $<0.0001$ \\
\hline & Daily temperature range $\left({ }^{\circ} \mathrm{C}\right)$ & 11.54 & 11.31 & 0.23 & 0.02 & 0.44 & 0.029 \\
\hline & Relative humidity (\%) & 68.18 & 66.70 & 1.47 & 0.82 & 2.13 & $<0.0001$ \\
\hline & Atmospheric pressure (hPa) & 1007.2 & 1007.9 & -0.7 & -1.4 & 0.1 & 0.073 \\
\hline & Particulate matter $\left(\mu \mathrm{g} / \mathrm{m}^{3}\right)$ & 48.54 & 51.83 & -3.29 & -4.76 & -1.81 & $<0.0001$ \\
\hline
\end{tabular}

a Significant $p$ values are indicated in bold.

also significantly higher on the days on which viral infection was detected than on those on which it was not. In contrast, the average particulate matter concentration was significantly lower on days on which viral infection was detected. No significant differences in mean precipitation and atmospheric pressure were found.

In the binomial logistic regression analysis, air and wind chill temperatures, atmospheric pressure, and particulate matter concentrations were significantly associated with rhinovirus infection (Table 3). Air and wind chill temperatures showed positive effects on rhinovirus
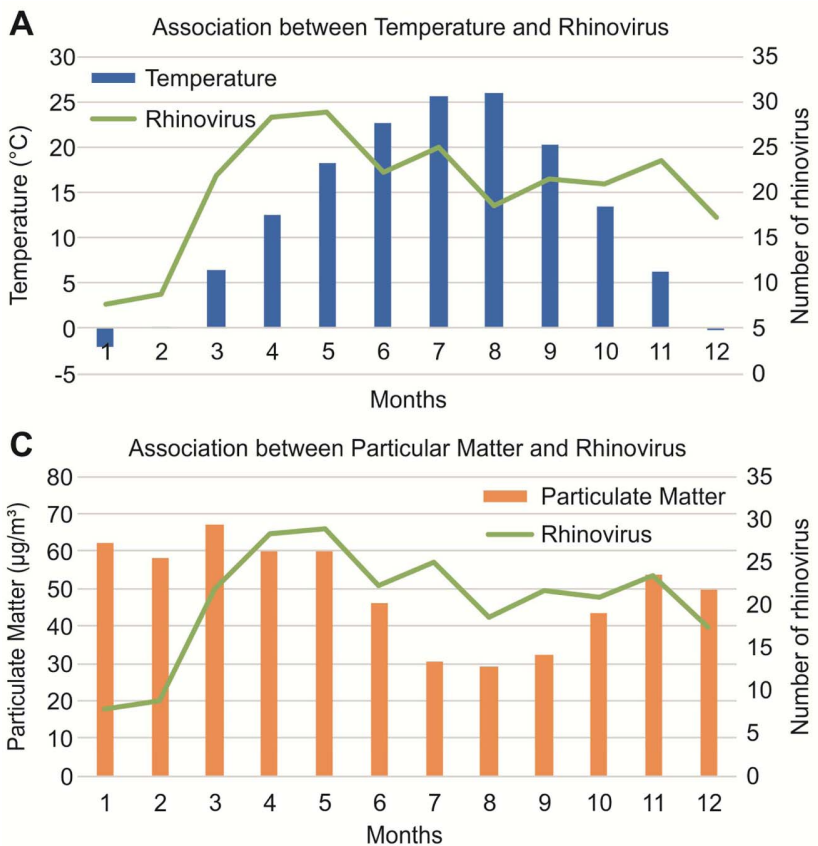

Fig. 2. Associations of temperature (A), wind chill temperature (B), particulate matter (C), and atmospheric pressure (D), with the rhinovirus detection rate.

infection, whereas atmospheric pressure and particulate matter concentrations demonstrated negative effects; that is, a higher number of rhinovirus infections occurred with higher air and wind chill temperatures, and with lower atmospheric pressure and particulate matter concentrations (Table 3).

\section{Discussion}

During the study period, rhinovirus infection was the highest in patients under the age of 10 years (>89\%),
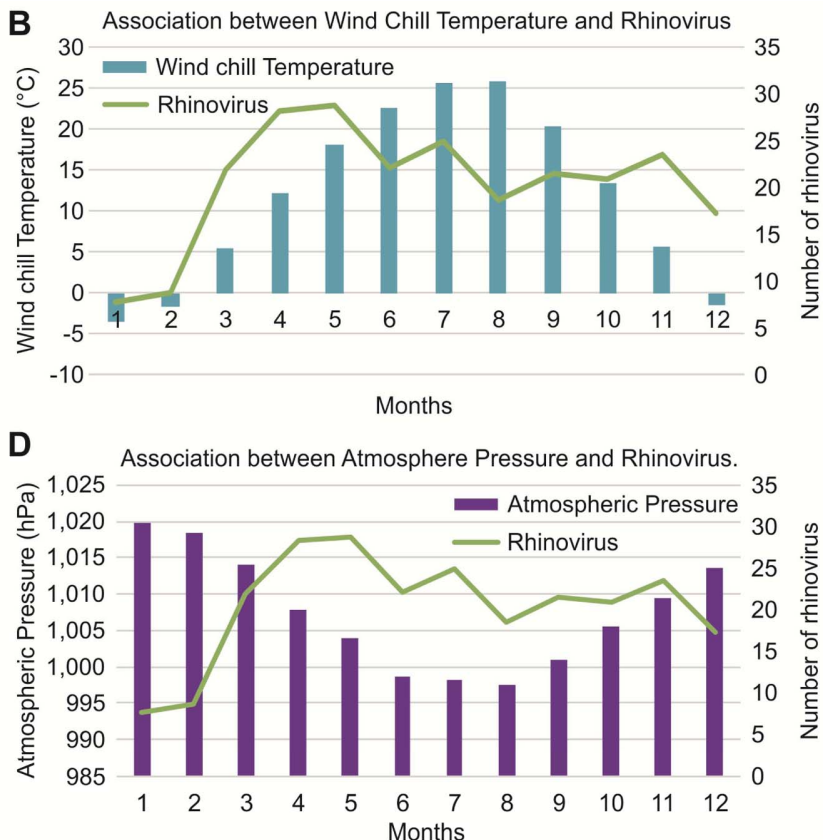
Table 3. Correlations between climatic factors and rhinovirus infections.

\begin{tabular}{lccc}
\hline \multirow{2}{*}{ Climatic Variables } & Odds & \multicolumn{2}{c}{$95 \% \mathrm{Cl}$ for odds ratio } \\
\cline { 3 - 4 } & Ratio $^{\mathrm{a}}$ & Lower & Upper \\
\hline Precipitation $(\mathrm{mm})$ & 0.989 & 0.887 & 1.102 \\
Air temperature $\left({ }^{\circ} \mathrm{C}\right)$ & 1.575 & 1.443 & 1.720 \\
Wind chill temperature $\left({ }^{\circ} \mathrm{C}\right)$ & 1.412 & 1.294 & 1.542 \\
Daily temperature range $\left({ }^{\circ} \mathrm{C}\right)$ & 1.077 & 0.987 & 1.175 \\
Relative humidity $(\%)$ & 1.073 & 0.983 & 1.171 \\
Atmospheric pressure $(\mathrm{hPa})$ & 0.732 & 0.671 & 0.799 \\
Particulate matter $\left(\mu \mathrm{g} / \mathrm{m}^{3}\right)$ & 0.824 & 0.754 & 0.900 \\
\hline
\end{tabular}

${ }^{a}$ Values with significant correlations are indicated in bold.

and infection rates increased each year during the transition from winter to spring and summer to fall. Many viruses demonstrate pronounced seasonality in temperate climates, and various studies have been conducted to determine the underlying cause; however, the relationship between climate and virus infection is not clear. Rhinovirus is the most common cause of colds and has recently been recognized as the most common exacerbator of asthma, a disease that affects approximately $10 \%$ of the population in the United States of America [3, 12]. Rhinoviruses multiply in the nasal cavity, which is relatively colder than the lungs that are equipped with enhanced antiviral defenses [23-26]. Differences in individual immunity because of changes in the weather may also have a significant effect on rhinovirus infection and severity, and on co-infection with other diseases [27-29]. Further research is needed to analyze the relationship between the incidences of influenza virus, respiratory syncytial virus, and rhinovirus.

Since rhinovirus symptoms begin to appear approximately $20 \mathrm{~h}$ after infection, the climatic variables on the day of the test may be unsuitable or inappropriate for use in comparisons to or correlations with the test results. Indeed, climatic changes were reported to occur prior to outbreaks of human rhinovirus infection [18]. However, the study was conducted in polar regions, and thus the timing relationships may differ from those in temperate climates.

Even with the same rhinovirus, the incubation period determined can vary depending on the research method used or the virus subtype. The Cheonan region did not display a sharp decrease in temperature during the win- ter, and the amplitude of the positive rate of detection was not large. Hence, we decided to explore possible associations between the detection of rhinovirus and specific climate variables. Therefore, establishing the viral incubation period requires various analyses in consideration of regional climatic conditions.

In this study, virus detection was significantly related to climatic variables such as atmospheric pressure, particulate matter, temperature, and wind chill temperature. The average atmospheric pressure and particulate matter concentrations were lower on days on which infection was detected than on days on which it was not. The average temperature, wind chill temperature, and humidity were higher on days on which the virus was detected than on days on which it was not. Temperature and wind chill temperature showed a positive effect on virus detection, whereas atmospheric pressure and particulate matter had a negative effect. There have been no studies to date on the relationship between viral infection and wind chill temperature; however, previous studies have reported that viral infection rates are proportionally related to humidity and that temperature is inversely proportional to humidity. In this study, infection rate, temperature, and humidity showed proportional relationships: wind chill temperature, which is affected by temperature, wind speed, and humidity, had a significant effect on virus detection, and the viral detection rate was high during seasonal changes. The different results for relative humidity among studies may be due to variation in the incidence of rhinovirus in winter among different regions.

In this study, the particulate matter concentration was high when the rhinovirus detection rate was rapidly increasing. The incidence of respiratory diseases in medical institutions has been shown to increase when the concentration of particulate matter (PM10) increases [30-33]. Greater concentrations of particulate matter increase the hospitalization rates for patients with asthma and chronic obstructive pulmonary disease [34, 35]; worsen symptoms and reduce lung function in individuals with pre-existing respiratory conditions; increase the rate of influenza infection [36]; increase mortality from pneumonia, influenza [37], cardiovascular, and lung disease; increase the rates of hospitalization owing to cardiovascular complications among patients with diabetes [38]; and increase the number of hospital outpa- 
tient visits by children [30]. Most previous studies on the relationship between PM10 and respiratory viruses in the atmosphere did not detect significant relationships due to technical limitations. Although there are studies on the relationship between PM10 and respiratory viral infections [31-33, 37], there have been few such studies in Korea [39]. In this study, rhinovirus detection was found to be lower when the concentration of particulate matter was higher. A previous study showed that in nasal epithelial cells exposed to PM10 in vitro [40], the rhinovirus infection rate increased as the concentration of PM10 increased. However, another study had inconsistent findings [39]. The distribution of PM10 varies greatly by region and over time; therefore, it is necessary to analyze the differences by region, rather than comprehensively. Further studies are needed to clarify the relationship between PM10 and rhinovirus infection.

There were some limitations to this study. First, the duration of the investigation and its focus on a single city could lead to a bias in the viral etiology. Second, as the data were anonymous, it was not possible to determine whether an individual was a visitor or a resident of the area; therefore, the tested samples may have included samples from patients who did not live in the collection area. However, given that a large number of samples was tested over a six-year period, the samples are considered representative.

There is no specific treatment for rhinovirus, but considering the high social cost of rhinovirus infection, it is essential to develop an antiviral agent that can reduce the treatment duration. As part of the Korea Center for Disease Control and Prevention strategies, research has been conducted to analyze and monitor the characteristics of viral upper respiratory tract infections and severe respiratory infections in children. Research and development into viral agents are also underway. Thus, understanding the epidemiology of rhinoviruses and their severity will provide essential information for the development of future treatments.

This study can be used as a basis for future research using a combination of medical data and meteorological data for specific respiratory viral infections. This study is the first to examine the relationship of rhinovirus detection with particulate matter and wind chill temperature in a specific region and confirms that the incidence of rhinovirus infection may increase with continuing climate change. Combining various types of climate change data with the accumulated medical data for specific respiratory viral infections can help predict respiratory viral outbreaks, and these predictions could be used for prevention and appropriate treatment. By linking medical data with weather and meteorological data, it may be possible to predict disease infection rates based on region and patient demographics. Ultimately, our results will assist in providing improved health care and treatment for respiratory viral infections.

\section{Acknowledgments}

This research was supported by the Basic Science Research Program through the National Research Foundation of Korea (NRF) funded by the Ministry of Education (grant number: R-2020-00217). The authors declare that there are no conflicts of interest.

\section{Conflict of Interest}

The authors have no financial conflicts of interest to declare.

\section{References}

1. Rotbart HA. 2002. Treatment of picornavirus infections. Antiviral Res. 53: 83-98.

2. Van Kempen M, Bachert C, van Cauwenberge P. 1999. An update on the pathophysiology of upper respiratory tract infections. Rhinology 37: 97-103.

3. Makela MJ, Puhakka T, Ruuskanen O, Leinonen M, Saikku $P$, Kimpimäki M, et al. 1998. Viruses and bacteria in the etiology of common cold. J. Clin. Microbiol. 36: 539-542.

4. Miller MJ. 1997. Viral taxonomy. Clin. Infect. Dis. 25: 18-19.

5. Park JS. 2009. Acute viral lower respiratory tract infections in children. Korean J. Pediatr. 52: 269-276.

6. Choi EH, Lee HJ, Kim SJ, Eun BW, Kim NH, Lee JA, et al. 2006. The association of newly identified respiratory viruses with lower respiratory tract infections in Korean children, 2000-2005. Clin. Infect. Dis. 43: 585-592.

7. Gwaltney JM, Hendley JO, Simon G, Jordan WS. 1967. Rhinovirus infections in an industrial population. II. Characteristics of illness and antibody response. JAMA 202: 494-500.

8. Turner RB. 2001. Treatment of rhinovirus infections: progress and potential. Antiviral Res. 49: 1-14.

9. Rivers MN, Alexander JL, Rohde RE, Pierce JR. 2009. Hantavirus pulmonary syndrome in Texas: 1993-2006. South Med. J. 102: 3641.

10. Sloan C, Moore ML, Hartert T. 2011. Impact of pollution, climate, and sociodemographic factors on spatiotemporal dynamics of seasonal respiratory viruses. Clin. Transl. Sci. 4: 48-54.

11. Jacobs SE, Lamson DM, St George K, Walsh TJ. 2013. Human rhi- 
noviruses. Clin. Microbiol. Rev. 26: 135-162.

12. Rotbart HA, Hayden FG. 2000. Picorna virus infections: a primer for the practitioner. Arch. Fam. Med. 9: 913-920.

13. Turner RB. 1998. The common cold. Pediatr. Ann. 27: 790-795.

14. Tyrrell DA, Cohen S, Schlarb JE. 1993. Signs and symptoms in common colds. Epidemiol. Infect. 111: 143-156.

15. Bardin PG, Fraenkel DJ, Sanderson G, Dorward M, Lau LC, Johnston SL, et al. 1994. Amplified rhinovirus colds in atopic subjects. Clin. Exp. Allergy 24: 457-464.

16. Turner RB, Hendley JO, Gwaltney JM. 1982. Shedding of infected ciliated epithelial cells in rhinovirus colds. J. Infect. Dis. 145: 849853.

17. Gern JE. 2010. The ABCs of rhinoviruses, wheezing, and asthma. J. Virol. 84: 7418-7426.

18. Ikäheimo TM, Jaakkola K, Jokelainen J, Saukkoriipi A, Roivainen $M$, Juvonen $R$, et al. 2016. A decrease in temperature and humidity precedes human rhinovirus infections in a cold climate. Viruses 8: 244 .

19. Lambkin-Williams R, Noulin N, Mann A, Catchpole A, Gilbert AS. 2018. The human viral challenge model: accelerating the evaluation of respiratory antivirals, vaccines, and novel diagnostics. Respir. Res. 19: 123.

20. He Y, Lin GY, Wang Q, Cai XY, Zhang YH, Lin CX, et al. 2014. A 3-year prospective study of the epidemiology of acute respiratory viral infections in hospitalized children in Shenzhen, China. Influenza Other Respir. Viruses. 8: 443-451.

21. Lee HK, Lee MJ, Mun SK, Kim WH, Cho HG, Yoon MH, et al. 2012. Serotype distribution of human respiratory adenovirus isolated in Gyeonggi Province. Korean J. Microbiol. 48: 175-179.

22. Lee JY. 2005. Between life and death of the virus, pp. 278. 1st Ed. Jiho Publishing, Seoul. Korea.

23. Gern JE, Swenson C, Shen G, Busse WW. 1997. Rhinovirus infection preferentially increases lower airway responsiveness in allergic subjects. Am. J. Respir. Crit. Care Med. 155: 1872-1876.

24. Puhakka T, Makela MJ, Alanen A, Kalio T, Korsof L, Arstila P, et al. 1998. Sinusitis in the common cold. J. Allergy Clin. Immunol. 102: 403-408.

25. Gwaltney JM, Miller RD, Riker DK. 1994. Computed tomographic study of the common cold. N. Engl. J. Med. 330: 25-30.

26. Pitkaranta A, Savolainen S, Povry T, Suomalainen I, Hyypia T, Carpen O, et al. 2001. Rhinovirus RNA in the maxillary sinus epithelium of adult patients with acute sinusitis. Clin. Infect. Dis. 33: 909-911.

27. Rodrigues AF, Santos AM, Ferreira AM, Marino R, Barreira ME, Cabeda JM. 2019. Year-long rhinovirus infection is influenced by atmospheric conditions, outdoor air virus presence, and immune system-related genetic polymorphisms. Food Environ. Virol. 11:
340-349.

28. Hung HM, Yang $\mathrm{SL}$, Chen $\mathrm{CJ}$, Chiu $\mathrm{CH}$, Kuo CY, Huang KYA, et al. 2019. Molecular epidemiology and clinical features of rhinovirus infections among hospitalized patients in a medical center in Taiwan. J. Microbiol. Immunol. Infect. 52: 233-241.

29. Ng KT, Oong XY, Lim SH, Chook JB, Takebe Y, Chan YF, et al. 2018. Viral load and sequence analysis reveal the symptom severity, diversity, and transmission clusters of rhinovirus infections. Clin. Infect. Dis. 67: 261-268.

30. Liu Y, Guo Y, Wang C, Li W, Lu J, Shen S, et al. 2015. Association between temperature change and outpatient visits for respiratory tract infections among children in Guangzhou, China. Int. J. Environ. Res. Public Health 12: 439-454.

31. Vandini S, Corvaglia L, Alessandroni R, Aquilano G, Marsico C, Spinelli $M$, et al. 2013. Respiratory syncytial virus infection in infants and correlation with meteorological factors and air pollutants. Ital. J. Pediatr. 39: 1.

32. Liu Y, Xie S, Yu Q, Huo X, Ming X, Wang J, et al. 2017. Short-term effects of ambient air pollution on pediatric outpatient visits for respiratory diseases in Yichang city, China. Environ. Pollut. 227: 116-124.

33. Zhu L, Ge X, Chen Y, Zeng X, Pan W, Zhang X, et al. 2017. Shortterm effects of ambient air pollution and childhood lower respiratory diseases. Sci. Rep. 7: 4414.

34. Jeon W, Kim H. 2016. Associations of air pollution on asthma hospitalization in Seoul and Shanghai. Korean J. Public Health. 53: 1726.

35. Oh JS, Park SH, Kwak MK, Pyo CH, Park KH, Kim HB, et al. 2017. Ambient particulate matter and emergency department visit for chronic obstructive pulmonary disease. J. Korean Soc. Emerg. Med. 28: 32-39.

36. Chen G, Zhang W, Li S, Zhang Y, Williams G, Huxley R, et al. 2017. The impact of ambient fine particles on influenza transmission and the modification effects of temperature in China: a multi-city study. Environ. Int. 98: 82-88.

37. Ciencewicki J, Jaspers I. 2007. Air pollution and respiratory viral infection. Inhal. Toxicol. 19: 1135-1146.

38. Shin DC. 2007. Health effects of ambient particulate matter. J. Korean Med. Assoc. 50: 175-182.

39. Cheon JM, Yang YJ, Yoon SK, Lee ES, Lee JH, Huh Y, et al. 2019. Influence of fine particulate dust particulate matter 10 on respiratory virus infection in the Republic of Korea. Korean J. Fam. Pract. 9: 454-459.

40. Yeo NK, Hwang YJ, Kim ST, Kwon HJ, Jang YJ. 2010. Asian sand dust enhances rhinovirus-induced cytokine secretion and viral replication in human nasal epithelial cells. Inhal. Toxicol. 22: 10381045. 